\title{
LEARNING WHERE TO OFFEND \\ EFFECTS OF PAST ON FUTURE BURGLARY LOCATIONS
}

\author{
Wim Bernasco ${ }^{12}$ \\ (corresponding author) \\ wbernasco@nscr.nl
}

Shane D. Johnson ${ }^{3}$

shane.johnson@ucl.ac.uk

\author{
Stijn Ruiter ${ }^{14}$ \\ sruiter@nscr.nl
}

1 Netherlands Institute for the Study of Crime and Law Enforcement (NSCR), P.O. Box 71304, 1008BH Amsterdam, The Netherlands

2 VU University Amsterdam, Department of Spatial Economics, De Boelelaan 1105, 1081HV Amsterdam, The Netherlands

3 UCL Department of Security and Crime Science, University College London, 35 Tavistock Square, London WC1H 9EZ, United Kingdom

4 Utrecht University, Department of Sociology, Padualaan 14, 3584CH Utrecht, The Netherlands 


\title{
LEARNING WHERE TO OFFEND
}

\section{EFFECTS OF PAST ON FUTURE BURGLARY LOCATIONS}

\begin{abstract}
Informed by a growing literature on space-time patterns of repeat and near repeat burglary victimization, a crime location choice model was used to test whether burglars are attracted to areas they previously targeted. Using data in 3,337 detected burglaries from one UK police force, and accounting for the distance to the offender's residence, and for other factors that make target areas attractive to burglars, it was demonstrated that burglars were more likely to commit a burglary in an area they had targeted before. This was particularly the case if the prior burglary was (very) recent. Areas near to those in which burglaries had been committed were also more likely to be selected.
\end{abstract}

\section{KEYWORDS}

crime ; burglary ; location choice ; discrete choice ; repeat offending ; journey to crime

\section{INTRODUCTION}

Human behavior in space is remarkably regular and predictable. For example, Song, Qu, Blumm, and Barabasi (2010) showed that knowing a person's recent locations greatly helps to predict their future whereabouts. If such spatial consistency also applies to burglars, locations of their past offenses should inform predictions of future ones. There is pending evidence that this is indeed the case.

More than two decades of research shows that past burglary victimization best predicts future burglary victimization risk (Pease, 1998). This repeat victimization risk peaks immediately after the initial burglary, and usually returns to a baseline level within a few months (Polvi, Looman, Humphries, \& Pease, 1991). In most repeat burglary victimizations the same offenders perpetrate both the initial burglary and the follow-up, particularly if the period between both events is short (Everson \& Pease, 2001). In other words, repeat burglary victimization typically involves burglars returning to their prior targets.

More recent research shows a phenomenon labeled as 'near repeat' (Bowers \& Johnson, 2004; Townsley, Homel, \& Chaseling, 2003), 'communicability of risk' (Johnson \& Bowers, 2004a), 'self-exiting point process' (Mohler, Short, Brantingham, Schoenberg, \& Tita, 2011) and 'spatio-temporal interaction' (Grubesic \& Mack, 2008). In the wake of a residential burglary, the victimization risk is temporarily increased not only for the initially burgled property, but for 
nearby homes too. The risk decays both in space and time, typically extending up to a few hundred meters, and persisting for a month or two (Johnson et al., 2007; Ratcliffe \& McCullagh, 1998). As with repeat victimization, the same offenders are often involved in both initial and 'near repeat' burglaries (Bernasco, 2008; Johnson, Summers, \& Pease, 2009). Apparently, burglars tend to return to their prior target areas. Furthermore, research on the behavioral consistency of serial offenders (aimed to improve crime linkage techniques in criminal investigations) has shown that the two most consistent and distinctive aspects of the modus operandi of serial burglars are where and when they offend (Markson, Woodhams, \& Bond, 2010; Tonkin, Santtila, \& Bull, 2012; Tonkin, Woodhams, Bull, Bond, \& Palmer, 2011).

Simultaneously, a formal model of burglary location choice has been developed and has been tested in empirical studies (Bernasco, 2006, 2010a, 2010b; Bernasco \& Nieuwbeerta, 2005; Clare, Fernandez, \& Morgan, 2009; Townsley et al., 2013). The main question that these studies address is how — based on which criteria — offenders decide where to commit a burglary. Applying random utility maximization theory (McFadden, 2001) and discrete choice models (Ben-Akiva \& Lerman, 1985), the effects are tested of variables that signal - from an offender perspective - benefits, costs and risks of potential burglary locations.

None of these burglary location choice studies, however, has explored how a burglar's previous burglaries might affect where he strikes next ${ }^{1}$. Instead, most studies analyzed the burglaries as isolated events that were unconnected to the past criminal endeavors and experiences of the offenders involved. This might be a serious omission, because the (near) repeat victimization studies cited above suggests that burglars often return to prior targets and target areas to commit subsequent burglaries. Common sense, learning theories, and perspectives from behavioral ecology such as optimal foraging theory (see, Johnson, 2014) suggest that offenders should learn from their criminal experiences. For example, one would expect burglars to return to target areas where they have been successful. One would also expect them to avoid alternatives where they failed in the past - where they did not achieve to enter the property, could not steal any valuable items, or where they were sighted or arrested.

Research on (near) repeat victimization has included theoretical and empirical (e.g., Bernasco, 2008; Johnson, 2014; Johnson, Summers and Pease, 2009) work intended to explain why offenders return to previously victimized locations, but a broader theoretical framework that connects the two lines of enquiry has remained underdeveloped. For example, if the same offenders are responsible for the initial and the subsequent burglary, what made them choose the target in the first place? Under what circumstances will they not return? What other criteria guide their choices? In other words, what is missing from the cited literature is an explicit theoretical model of (repeated) burglary location choice.

\footnotetext{
${ }^{1}$ Because clarity of expression is served by using singular instead of plural forms, and to prevent awkward stylistic constructions, we use male personal pronouns throughout this paper.
} 
A recent study in the Netherlands (Lammers, Menting, Ruiter, \& Bernasco, 2015) addressed this issue, using a sample of detected crimes (of any type) and the offenders involved. The areas where offenders had committed prior offenses were included in a model of their subsequent crime location choices. The findings showed that offenders tend to return to previous target areas, in particular to those of recent crimes and especially if the previous crimes were of the same crime type.

The study reported here aims to further explore questions of repeat crime location choices and differs in three key aspects from the study by Lammers et al. (2015). First, it used data from another country (United Kingdom). Second, it used a smaller spatial unit of analysis. Whereas Lammers et al. (2015) used areas with an average population of 7,000 residents, the areas used here have an average population of only 1,500, potentially providing for more homogeneous spatial units and enhanced ecological validity. Third, and most importantly, whereas Lammers et al. (2015) studied all crime types combined, the present study focused on burglary only. This focus allows for more specificity in the literature review, the theory development, the selection of variables, and in the interpretation of empirical findings.

In sum, we develop explicit hypotheses on how the time and location of past burglaries affect a burglar's subsequent decisions of where to commit burglaries, and integrate the theory that motivates these into a more general model of burglary location choice. Using police-recorded burglary data we rigorously test three hypotheses using discrete spatial choice modeling techniques.

The remainder of the paper is structured as follows. Drawing on the criminological literature on burglary, section 2 reviews existing theory on how burglars decide where to offend, and develops new theory about how previous burglary locations influence that decision. Section 3 addresses data and method, section 4 describes the findings, and section 5 reflects on the results and suggests avenues for future research.

\section{WHERE TO COMMIT BURGLARY}

How do offenders decide where to commit a burglary, and how do times, places and other characteristics of their prior burglaries enter into that decision? We start by reviewing the criminological literature, which applies rational choice theory to this topic. We subsequently discuss how crime pattern theory suggests that burglars are most likely to offend within their awareness space, which includes places they have visited in the recent past. Finally, we provide arguments why they are likely to return to areas where they recently committed burglaries.

\subsection{Rational location choice}

Our burglary location choice model builds on prior work (Cornish \& Clarke, 1986) that was inspired by rational choice theory, which claims that when people make decisions they choose the alternative from which they expect most utility (benefits minus costs, or pleasure minus pain). 
For an individual who is motivated to commit a burglary and who must decide on where to commit it, Bernasco and Nieuwbeerta (2005) distinguish benefits, costs and risk as the arguments of the burglar's utility function. Benefits of a burglary include material gain (items stolen) and possibly also immaterial gain (excitement, peer group status). Costs include the time, expenses and effort it takes to travel to the burglary location, commit the burglary and to trade stolen items. Risk is a function of the probability and penalties associated with arrest, prosecution and punishment, as well as the probability and severity of injury in case of unexpected confrontations with victims or witnesses. Each potential burglary location (i.e., each choice alternative) is associated with characteristics that make it more or less profitable, costly and risky to burgle. Burglars thus have to make trade-offs when deciding where to offend.

Bernasco and Nieuwbeerta (2005) defined urban neighborhoods as the alternatives, and thus examined which neighborhood characteristics affect a burglar's choice of neighborhood in which to offend. Considering the benefits, they suggested that affluent neighborhoods would offer rich pickings and hence be attractive to burglars. In contrast, neighborhoods characterized by high levels of guardianship (as indicated by low population turnover and low ethnic heterogeneity) would be avoided due to the risks involved. For similar reasons, they argued that neighborhoods characterized by higher levels of ethnic heterogeneity would be more attractive for non-native than native burglars. Apropos the costs, they argued that accessible neighborhoods (located nearby the burglar's home) and neighborhoods with accessible residential properties would be more attractive than their counterparts. They further hypothesized that accessibility in terms of distance travelled - would have a greater influence for juvenile burglars than for adults. A recent cross-national replication (Townsley et al., 2013) tested the same behavioral model using comparable data from The Hague, Netherlands, Brisbane, Australia and Birmingham, UK. Its findings confirmed that across the study regions, burglars are attracted by nearby target areas that have many, in particular easily accessible, targets. However, they also revealed that these effects varied in magnitude across the three study regions. Effects of other area characteristics even showed differences across the study areas in both sign and magnitude.

Other studies of burglary location choice have extended the analytical framework and added further insights. Bernasco (2006) demonstrated how the model of Bernasco and Nieuwbeerta (2005) (which analyzed 548 burglaries committed by 290 solitary burglars) can be adapted to include location choices of co-offending burglar groups, but found no differences between solitary burglars and groups.

Clare et al. (2009) argued that distance alone insufficiently measures the costs involved in traveling between areas, because transport costs are reduced by 'connectors' such as transit lines that reduce travel time between origins and destinations, and increased by 'barriers' such as wide rivers that impede travel between the areas they divide. Note that some infrastructures may actually function as both connectors and barriers. Main roads, for example, facilitate transport between the areas situated along them, but because they cannot be crossed easily they can inhibit movement between the areas they bisect. In a study of burglary location choice in Perth, 
Australia, they found that indeed selected roads and the Swan River that runs through the study area inhibited burglary trips between areas divided by these barriers, while the local railway line facilitated burglars to travel between the areas on the railway line. Other infrastructural features may also influence location choices of burglars. In England (Davies \& Johnson, 2014; Johnson \& Bowers, 2010) and in China (Wu et al.), it was demonstrated that street permeability affects burglary risk. A study in South-Africa (Breetzke, 2012) showed that higher altitude of potential target areas appears to reduce the risk of burglary victimization.

\subsection{Crime pattern theory and awareness space}

All but the study of Lammers et al. (2015) analyzed crime location choices as isolated decisions unaffected by the offenders' past crime experiences. For example, the initial study (Bernasco \& Nieuwbeerta, 2005) included 548 burglaries committed by 290 offenders, but the authors essentially treated all burglaries as independent observations. Although they corrected for the downward bias in standard errors caused by the dependence between multiple burglaries committed by the same offender, their analytical methods could not have detected whether the location of a previous burglary affected subsequent burglaries. The same holds true for crime location choice studies of other types of crime (Baudains, Braithwaite, \& Johnson, 2013; Bernasco \& Block, 2009; Bernasco, Block, \& Ruiter, 2013; Johnson \& Summers, 2014).

Prior to Lammers et al. (2015), two other studies examined the effects of past residential experiences. They demonstrated that offenders, including burglars (Bernasco, 2010b) and commercial robbers (Bernasco \& Kooistra, 2010) tend to target areas of prior residence.

The theoretical inspiration for these studies was informed by crime pattern theory (Brantingham \& Brantingham, 2008), in particular the concept of criminal awareness space, and how this might shape crime location choices. Crime pattern theory proposes that crime is perpetrated at those places and times where a motivated criminal's awareness space overlaps with the spatiotemporal distribution of attractive criminal opportunities. In the case of burglary, it asserts that burglars must be aware of a location in order to be able to choose it as a burglary target. Whereas the rational choice location theory focuses on criminal opportunities and silently assumes that all burglars have full information of all potential target areas, crime pattern theory emphasizes that offenders will have incomplete knowledge limited to their personal awareness spaces. Awareness space is defined as the set of places a person regularly performs or has recently performed activities, the habitual routes they take between these places and the area within visual range of these places and routes (see Bernasco, 2010b).

In particular, Bernasco (2010b) argued that not only current but also past activity places attract offenders because they have useful knowledge of these locations and the surrounding areas. Because knowledge acquisition takes time and repeated exposure, and because it is subject to decay when not maintained, he suggested that the recency, duration, and the proximity of past residential experience all positively affect the likelihood of choosing an area for burglary. Using 
empirical data on burglary (and three other types of crime) these hypothesized effects were tested. All other things being equal (i.e., controlling for other factors that would make an area attractive for all burglars because of high benefits, low costs, and low risk), burglars were found to be more likely to burgle in an area they had lived before than in areas they had not. They were also more likely to burgle in an area they had lived for a long period of time than in one in which they had resided only briefly, and more likely to commit a burglary in an area they had lived until recently than in one they had vacated a long time ago. Furthermore, areas they had never lived were more likely to be targeted if they were situated nearby a former home than those that were farther away from their previous residences.

Burglars' awareness spaces apparently include their former home locations. They probably also include other former anchor points, such as workplaces, schools or friends' homes. Given that such past experience appears to influence offender location choice, it seems reasonable to suggest that when the location of a prospective burglary is considered, the locations of an offender's past burglaries may also be considered. In fact, they may be particularly salient, because they are likely to have been selected on the basis of the same considerations as the current or next offense. In other words, previous burglary locations may be highly predictive of where a burglar decides to offend next. As summarized in the next section, research on repeat and near repeat victimization supports this proposition.

\subsection{Burglary experience}

For a variety of crime types, in particular burglary, it has often been demonstrated that the risk of victimization is elevated amongst prior victims (Farrell \& Pease, 2001). To some extent, the elevated risk might reflect that these repeat victims have features that attract offenders: the initial victimization merely 'flags' the pre-existing elevated risk, but does not cause it. However, the fact that the elevated risk decreases fairly rapidly within weeks of the initial event suggests that the initial victimization temporarily 'boosts' the risk of victimization (Johnson, 2008; Pitcher \& Johnson, 2011; Tseloni \& Pease, 2003).

A possible explanation of the phenomenon is that repeat victimization is caused by the return of the same offenders that perpetrated the initial crime (Farrell, Phillips, \& Pease, 1995:391). Successfully entering, exploring and burgling a property may provide an offender with the knowledge and incentives to do it again, possibly in the expectation that the owners will have replaced previously stolen items (Clarke, Perkins, \& Smith Jr., 2001). Empirical research on detected repeat residential burglaries (Everson \& Pease, 2001) demonstrates that in a majority of repeat residential burglary cases, the same offenders are responsible for both the initial and the subsequent burglary.

More recently, the repeat burglary victimization phenomenon has been generalized to include 'near repeats' (Bowers \& Johnson, 2005; Bowers, Johnson, \& Pease, 2004; Grubesic \& Mack, 2008; Johnson, 2013; Johnson et al., 2007; Johnson \& Bowers, 2004a, 2004b; Mohler et 
al., 2011; Pitcher \& Johnson, 2011; Townsley et al., 2003; Ye, Xu, Lee, Zhu, \& Wu). Studies of near repeat victimization show that the risk of burglary (and other offenses) is temporarily elevated not only amongst prior victims, but also those nearby. Again, it has been suggested that this can be explained by offenders returning to their prior burglary locations or those nearby. In fact, some near repeats might have started as repeats proper, but may have been displaced to other properties in the vicinity if the offenders discovered that the original burglary target was somehow blocked, for example, because the victimized residents upgraded security after the initial burglary.

Based on the finding of consistency in the modus operandi of near repeat burglaries, Bowers and Johnson (2004) suggested that repeat offending may also be involved in near repeat victimization. Using data on detected burglaries, two studies (Bernasco, 2008; Johnson et al., 2009) confirmed this by directly demonstrating that both repeat and near repeat burglaries are very often caused by the same offenders returning to previously targeted objects. Bernasco (2008) selected all pairs of solved burglary cases committed in the Greater The Hague Area (the Netherlands), and found that both repeat and near repeat victimization were much more likely to involve the same offenders than pairs of unrelated burglaries. For example, of all repeat burglaries at the same address that took place less than 15 days apart, 95 percent involved the same offender. Of those that were less than 3 months apart, still 91 percent involved the same offender. For near repeat burglaries that took place less than 400 meter away from each other, these percentages were 64 percent (15 days) and 30 percent ( 3 months). Johnson et al. (2009) report almost identical findings for detected burglaries (and vehicle crimes) in the county of Dorset (UK). Furthermore, using data on all burglaries in the area (both detected and undetected), they also show similar space-time patterning of detected and undetected burglaries, which suggests that their findings do not simply reflect a detection bias in the data analyzed.

Summing up, the literature on repeat burglary victimization and near repeat burglary victimization strongly suggests that offenders have a tendency to return to prior targets. More precisely, they seem more likely to target a property they recently burgled than a similar property that they did not, and more likely to target a property in an area that they recently selected for burglary than one in a similar area that they did not select before.

Another literature that informs the question of whether offenders return to previously targeted objects or areas is that on behavioral consistency in offending behavior (Bennell, Mugford, Ellingwood, \& Woodhams, 2014; Woodhams, Hollin, \& Bull, 2007). The purpose of studies of behavioral consistency in offending is to inform crime linkage procedures, i.e. to determine which unsolved crimes are likely to have been committed by the same offenders. These procedures assume that offenders commit offenses in a consistent but distinctive way, which means that their own crimes are similar, but different from those of other offenders.

While many types of consistency have been studied, spatial and temporal choice (where and when offenders commit crime) has been shown to be more consistent and more distinctive 
than most other aspects of serial burglars' offending behavior (Bouhana, Johnson, \& Porter, 2014; Markson et al., 2010; Tonkin et al., 2012; Tonkin et al., 2011). More precisely, burglaries committed by the same offender are found to occur closer to each other in space and time than those committed by different offenders. While performed from a crime linkage perspective, these findings are in line with those of Bernasco (2008) and Johnson et al. (2009) discussed above.

Most research reviewed in the preceding sections has been based exclusively on police data. Burglars are alternative sources of information on how spatial choices are made. Offenderbased research may include prisoners or active burglars. Usually, when offenders are interviewed they are asked about their lives and burglary methods (Rengert \& Wasilchick, 2000; Summers, Johnson, \& Rengert, 2010; Wright, Brookman, \& Bennett, 2006; Wright \& Decker, 1994). Occasionally, offenders are asked to participate in quasi-experimental research of perceptions, skills and strategies of 'expert' burglars by making a series of judgments (Garcia-Retamero \& Dhami, 2009; Nee \& Meenaghan, 2006).

Although the offender-based literature on burglary is comprehensive, not much is known about spatial learning and repeat burglary location choices. In a review of the offender-based literature, Bernasco (2008) found five offender-based studies that had included questions on repeat offending of the same target. Among these five studies, the percentage of burglars that admitted having returned to a previously burgled property, ranged between 31 and 76 percent. As Bernasco notes, this wide range may reflect differences in the wording of interview questions as well as differences in the sample frames used for the research. The findings suggest that burglars return to previously burgled properties, but are not detailed enough for reliable estimates. We know of no studies that interviewed burglars explicitly about the near repeat phenomenon.

\subsection{Hypotheses}

Based this review of the literature, and to the extent that prior burglaries represent positive learning experiences, we suggest that the recency, intensity and proximity of exposure to previous burglary locations increase the likelihood of a burglar returning to the previous location. Recency is important both because recent exposure is better retained and because the information itself is more likely to be accurate because less time has passed for circumstances to change (see Johnson, 2008; Johnson, Bowers, \& Hirschfield, 1997). For example, if an offender burgled a house yesterday and found no alarm system present, an alarm system is unlikely to be present today, but it might be installed within two weeks. The intensity refers to the number of times an offender has burgled within a specific area and represents the amount of learning experience. The proximity of prior burglary locations also plays a role because during prior burglaries an offender is likely to have acquired knowledge not only on the burgled property itself or the immediate neighboring properties, but also on the wider area.

Based on these arguments and those laid out in the previous section, three separate expectations can be articulated. First, as a reflection of burglary experience in general we expect 
that burglars are more likely to target areas they previously burgled than areas that they never targeted before. Because all experience is subject to decay when not regularly maintained, the second expectation is that recent burglaries have greater weight, and thus that a burglar is more likely to target an area he recently burgled than one he burgled long ago. And finally, in correspondence with the reviewed literature and assuming that there is spatial spillover in what offenders learn about the environment when they burgle, it is expected that a burglar is more likely to target an area located near to an area he has burgled before than one located at a greater distance from the area he has burgled before. These hypotheses are expected to hold under the 'ceteris paribus' clause whereby other factors that can be assumed to apply to all burglars alike are accounted for. These other decision criteria include indicators of benefits, costs and risks of target locations (discussed in our review of the rational location choice literature) and they are thus tested again in the form of 'control variables', but are not explicitly formulated as hypotheses because they are not the main focus of our analysis.

\section{DATA AND METHODS}

Data were acquired for all detected residential burglaries committed between January 2007 and December 2012 in the West Midlands, a large metropolitan UK police force (see Figure 1). A residential burglary is the actual or attempted illegal entry into a dwelling with the intent to steal (Bernasco, 2014). A 'detected' burglary is one that has been reported to the police, and where at least one person has been charged with committing it. The following variables were available for analysis for each burglary: a unique identifier for the offender involved; the time and date of the burglary; the address and geographic grid coordinates of the burglary (accurate to a resolution of one meter); and spatial coordinates for the home address of the offender at the time of the burglary (also accurate to a resolution of one meter).

To prevent a temporal edge effect it was necessary to assure that for each burglary the data would allow us to look back over a fixed period of time to establish the offender's previous burglaries. For this reason, it was decided that burglaries committed during the first 2 years (2007-2008) would be used to establish each offender's history of past burglaries in the study area. The data for the remaining observation period (2009-2012) were used to analyze their subsequent burglary location choices. A period of 2 years was chosen in part because a longer period of 'historic' burglaries would imply a lower number of focal burglaries to be analyzed (and thus lower statistical power), and was also in line with the length of the periods selected in related studies on the role of former offender residences (Bernasco, 2010b) and former crime locations (Lammers et al., 2015) in crime location choice.

Table 1 shows, for each burglary committed during the observation period (2009-2012), how many prior burglaries the offender had committed anywhere in the study area over the past 2 years, including any prior burglaries committed during the 2 years preceding the observation period (2007-2008). For example, if an offender committed a burglary in 2008, one in 2009 and one in 2010, the 2008 burglary would not be an observation in the table, the 2009 burglary would 
show up as having 1 prior burglary (namely the 2008 burglary) and the 2010 burglary would have 2 prior burglaries (the 2008 and 2009 burglaries).

Table 1: Prior burglaries in previous 24 months ( $\mathrm{N}=3,337$ focal burglaries 2009-2012)

\begin{tabular}{lcc}
\hline Prior burglaries & $\mathrm{N}$ & $\%$ \\
\hline 0 & 2,466 & 73.89 \\
$1-2$ & 210 & 6.29 \\
$3-5$ & 222 & 6.65 \\
$6-10$ & 229 & 6.86 \\
$11-20$ & 125 & 3.74 \\
$21-30$ & 61 & 1.83 \\
$31+$ & 24 & 0.72 \\
\hline Total & 3,337 & 100 \\
\hline
\end{tabular}

To distinguish recent prior burglaries from those more distant in time, based on the literature on 'near repeat' burglaries reviewed in the previous sections, the following six temporal categories were used: '0-2 days', '3-6 days', '7-30 days', '1-6 months', '7-24 months' and 'None $<24$ months', with the last category including all cases where the offender had not committed a burglary during the past two years in the area under consideration.

The concept of crime location choice presumes spatial units of analysis, which are the alternative locations that burglars choose from when deciding on where to commit a burglary. Whereas the contemporary literature on the geography of crime emphasizes the analytical superiority of small spatial units (e.g., micro-places like face blocks or street segments), the implementation of units of such small size in spatial choice models is fraught with complex issues, including the need to use 'sampling from alternatives' to solve the intractability of the estimation problem, and the requirement to estimate multiple-level spillover effects (Bernasco et al., 2013). As a compromise, we decided to use the UK Census Lower Level Super Output Area (LSOA) geography as the basic spatial unit of analysis. LSOAs are defined on the basis of proximity and social homogeneity measures (type of dwelling and nature of tenure) and have a population of approximately 1,500 residents and 600 households. LSOAs are smaller than the postal code areas used in some other crime location choice studies (Bernasco, 2010b; Lammers et al., 2015) but larger than the micro-scale places used in others (Bernasco, 2010a; Bernasco et al., 2013). Spillover effects can be assessed using either hierarchical spatial nesting structures or spatial proximity structures (Bernasco \& Elffers, 2010). Because the boundaries of the UK census areas are designed to optimize social homogeneity in terms of household tenure and dwelling type (Haining, 2012; Sturgis, Brunton-Smith, Kuha, \& Jackson, 2013), we preferred the former, and estimated spillover using variables measured at the next higher level of the census geography in the UK, the Middle Layer Super Output Area (MSOA). MSOAs comprise groups of typically 4-5 LSOAs and have a minimum size of 5,000 residents (and 3,000 households) with an average population size of 7,500. 


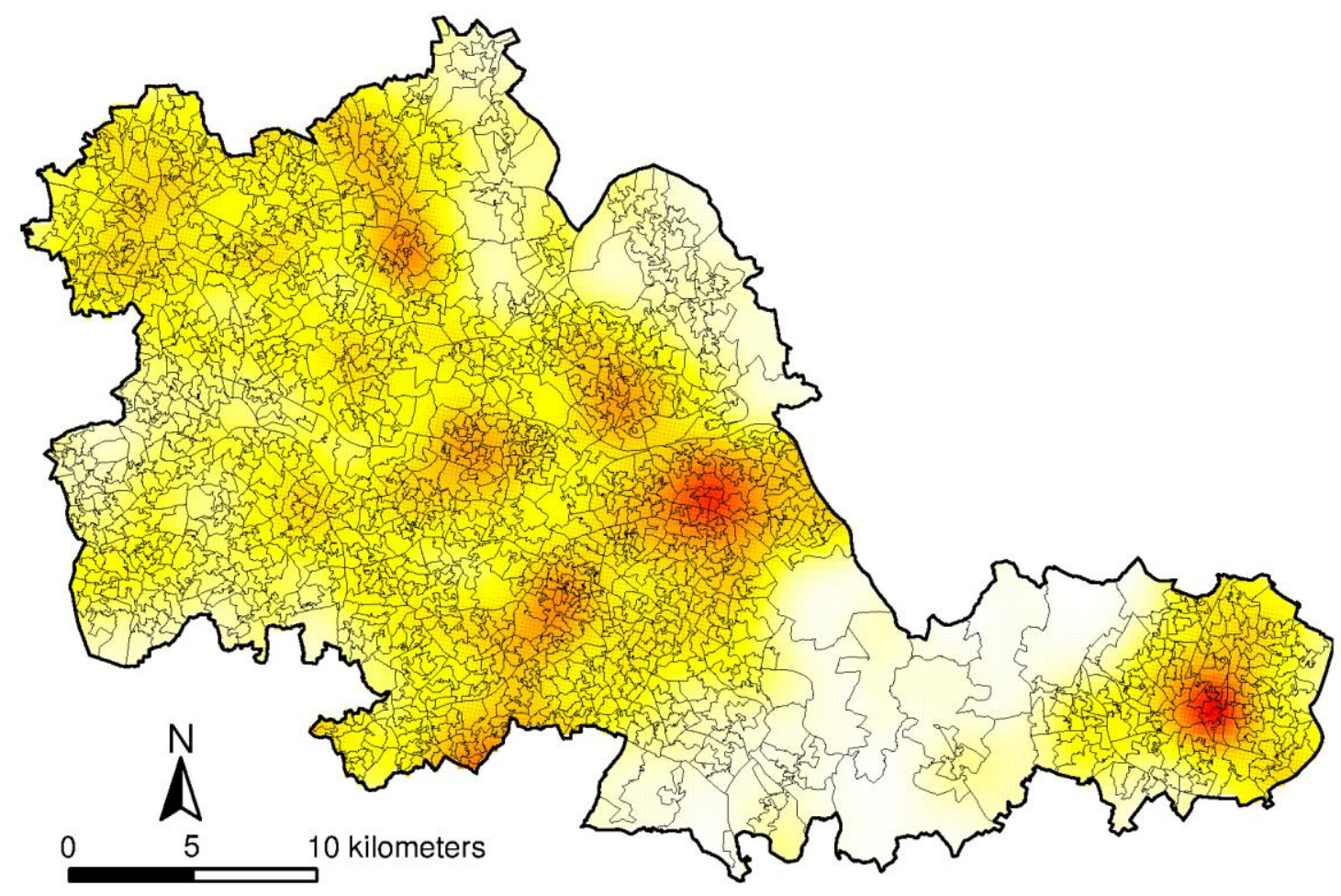

Figure 1: West Midlands (UK) kernel density map of burglary

Figure 1 displays a kernel density map (Gaussian kernel function with 1 kilometer bandwidth) of the spatial distribution of burglary targets in the study area, with the polygon boundaries of the LSOAs superimposed.

Table 2 shows how often the offenders committed burglaries in the LSOAs and MSOAs they had targeted before during the previous two years. For example, it demonstrates that 171 (94 +77 ) of the 3,337 burglaries (5.1 percent) were committed in an LSOA that the same offender had targeted up to one week before, and $95(33+62 ; 3$ percent $)$ were committed in an MSOA that the same offender had targeted up to one week before (minus those that occurred in the same LSOA as a previous offense). 
Table 2: Prior burglaries in same LSOA and MSOA (N=3,337 focal burglaries 2009-2012)

\begin{tabular}{lcc}
\hline & $\mathrm{N}$ & $\%$ \\
\hline Prior Burglary Same LSOA: & & \\
0-2 days & 94 & 2.81 \\
3-7 days & 77 & 2.30 \\
8-30 days & 115 & 3.45 \\
1-6 months & 151 & 4.52 \\
7-24 months & 38 & 1.14 \\
None < 24 months & 2,862 & 85.76 \\
& & \\
Prior Burglary Same MSOA: & & \\
0-2 days & 33 & 0.99 \\
3-7 days & 62 & 1.85 \\
8-30 days & 116 & 3.47 \\
1-6 months & 132 & 3.95 \\
7-24 months & 56 & 1.67 \\
None < 24 months & 2,938 & 88.04 \\
\hline
\end{tabular}

Because co-offending greatly complicates the analysis of crime location choice (Bernasco, 2006), it was decided that only the locations of burglaries committed by a single offender would be analyzed, and to exclude burglaries committed by multiple offenders (28 percent of the initial sample). However, offenses committed by multiple offenders were used to construct the 'prior burglaries' independent variable (as we assume that offenders learn from these burglaries too).

Considering the independent variables, with the exception of the count of bus stations, train stations, and house prices, data were obtained from the 2001 UK census. Population turnover was computed using the formula outlined in (Dennett \& Stillwell, 2008):

$$
T_{i}=\left(\frac{I_{i}+O_{i}+W_{i}}{P_{i}}\right) \times 100
$$

where $I_{i}$ is the in-migration to area $i, O_{i}$ is the out-migration from the area, $W_{i}$ is the number of residents who move from one home to another within area $i$, and $P_{i}$ is the total population living in area $i$. To simplify interpretation, in the analysis that follows, these values were divided by ten so that a one-unit change in this variable would represent a ten-unit change in population turnover.

Ethnic diversity was calculated using the index of qualitative variation (Wilcox, 1973), which is computed as follows:

$$
E_{i}=\left(1-\sum_{k=1}^{n} p_{k i}^{2}\right) \times 100
$$


where $n$ is the total number of different ethnic groups living in area $i$, and $p_{k i}^{2}$ is the fraction of individuals that belong to ethnic group $k$ that live in the area ${ }^{2}$. As with population turnover, these values were divided by ten to ease interpretation of results.

Data on house price sales were acquired from the UK Land Registry for the period 1995-2012. The data, provided as individual records, were aggregated to the LSOA geography using a Geographical Information System (GIS). Data on the location of bus and rail stations were obtained from the Department for Transport National Public Transport Access Node database (http://www.dft.gov.uk/naptan) and linked to the census data using a GIS.

Table 3: Characteristics of LSOAs $(\mathrm{N}=1,687)$

\begin{tabular}{lcccc}
\hline & mean & sd & min & max \\
\hline Surface $\left(\mathrm{km}^{2}\right)$ & 0.51 & 0.97 & 0.01 & 18.65 \\
Bus Stations (\#) & 0.02 & 0.12 & 0 & 1 \\
Train Station (\#) & 0.04 & 0.19 & 0 & 1 \\
Distance city center (km) & 12.56 & 7.54 & 0.44 & 33.49 \\
Households (\#) & 612.36 & 85.59 & 400 & 1,366 \\
Single Family Residences (\#) & 379.61 & 68.31 & 64 & 593 \\
Mean house price (1,000 £) & 105.82 & 45.76 & 47.63 & 430.53 \\
Ethnic Diversity (10\%) & 2.50 & 1.83 & 0.12 & 7.42 \\
Population Turnover (10\%) & 1.82 & 0.92 & 0.61 & 13.22 \\
\hline
\end{tabular}

To test the hypotheses, a discrete spatial crime location choice approach is used (Bernasco et al., 2013; Bernasco \& Ruiter, 2014) in which every burglary is conceptualized as a discrete choice amongst all 1,687 LSOAs in the study area, and a multinomial logit model is used to estimate the relative weight of each of the LSOA characteristics in the burglar's decision. We present these relative weights as odds ratios that represent the effect of a one-unit increase in an independent variable on the odds of the LSOA being chosen for burglary.

\section{FINDINGS}

The estimated model parameters (odds ratios, confidence intervals, and significance level indicators) are listed in Table A1 in the Appendix. For improved interpretation, this information

\footnotetext{
${ }^{2}$ We use the following categories of ethnicity as defined in the 2001 UK census: White, Mixed race, Asian, Black, and Chinese.
} 
is presented graphically in Figure 2. Pseudo $\mathrm{R}^{2}$ values for the discrete choice model are expected to be much lower than those for ordinary least squares models. In this case, according to McFadden's guidance, the observed pseudo $\mathrm{R}^{2}$ of .31 represents an excellent fit to the data (McFadden, 1978: 307).

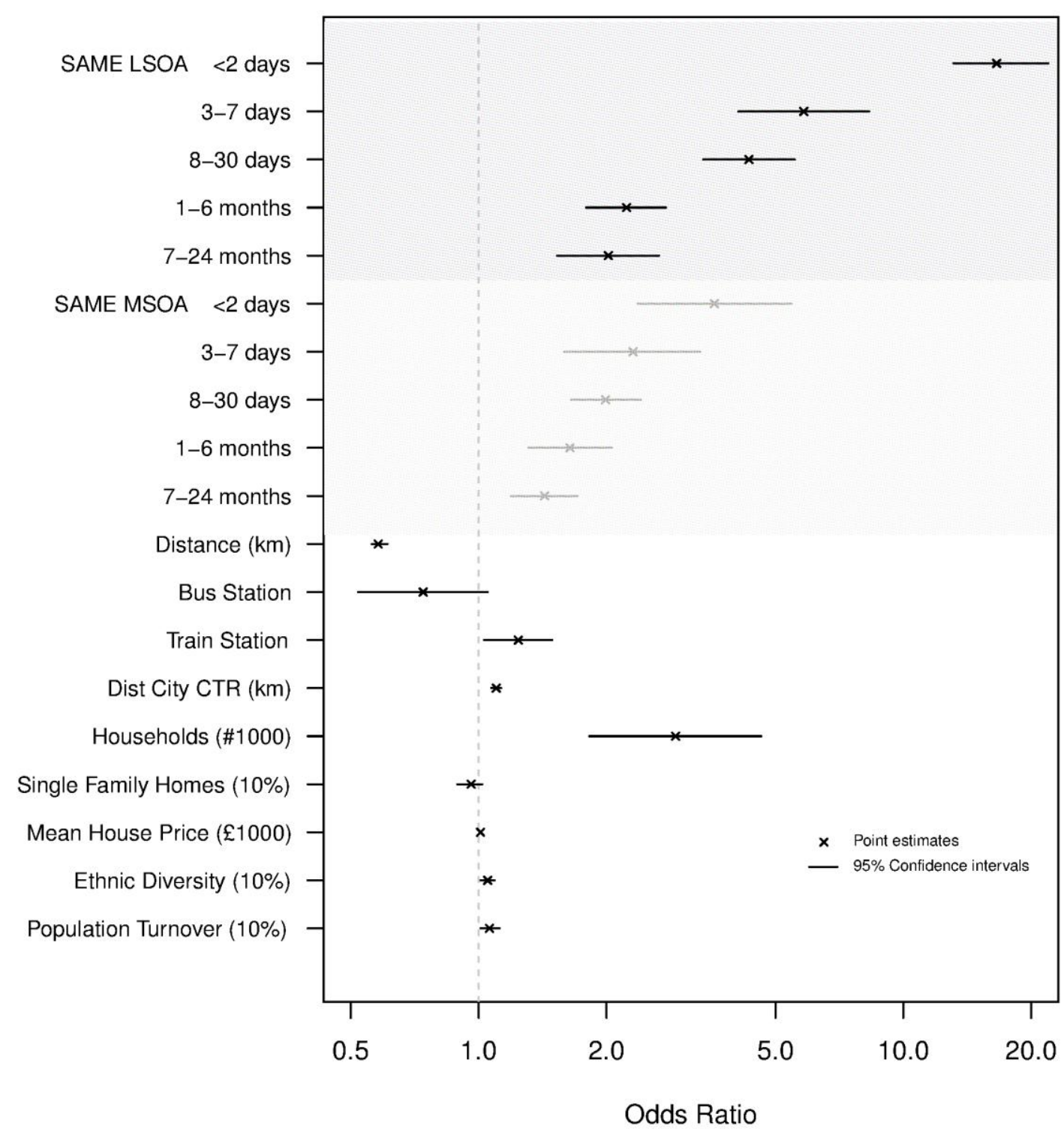

Figure 2: Conditional Logit Model Estimates (Odds Ratios and 95\% Confidence Intervals) of Burglars' Choice of Target LSOA. Model Applies to 3,337 Burglaries Committed by 2,143 Offenders. Number of LSOAs $=1,687$. McFadden's Pseudo $R^{2}=.31$. Note: $\mathrm{x}$-axis is on a $\log$ scale. 
In Figure 2, the dots represent the estimated odds ratios. More precisely, they represent the multiplicative effects of the independent variables on the odds that a burglar targets a particular LSOA. The horizontal position of a dot indicates the direction and strength of the effect. Dots situated to the right (left) of the reference value of 1 are associated with an increase (decrease) in the probability of an area being selected. The horizontal lines shown in Figure 1 represent the 95 percent confidence interval of the estimated odds ratios. Thus, all effects where these lines touch or cross the (dotted) vertical line at value 1 are not statistically significant (twosided) at $\mathrm{p}<.025$. For example, the odds ratio of Distance equals .58 . This is a negative effect: it implies that for every one kilometer an LSOA is located farther away from the burglar's own home, the odds that he targets the LSOA decreases by a factor .58, or by 42 percent. The lower and upper bounds of the 95 percent confidence interval are .56 and .61 respectively, and the effect is thus statistically significantly different from unity.

Zooming in on what is most relevant for the three hypotheses to be tested here, we first discuss the effects of the times and locations of prior offending. As expected, burglars are more likely to target areas they previously targeted for a burglary than areas they did not target before. In other words, areas of prior burglaries have an elevated likelihood of being selected. Compared to LSOAs that a burglar has not targeted during the past two years, the odds of him selecting an LSOA inflate by a factor 16.6 if he has burgled in the LSOA during the past two days. They inflate by a factor 5.8 if the prior burglary was 3-6 days ago, by a factor 4.3 if it was 7-30 days ago, and by 2.2 if it was 1-6 months ago. Even if a burglar committed a prior burglary 6-24 months ago in an LSOA, it still doubles the odds of the LSOA being targeted again during the focal burglary, as compared to an LSOA that the burglar did not target within the last 24 months. In sum, burglars are clearly more likely to target areas they previously targeted.

The recency of prior burglaries is relevant as well. In support of the claim that recent burglaries weigh stronger than burglaries committed in the distant past, the results demonstrate that a burglar is more likely to target an area he has recently targeted for a burglary than one he targeted long ago - the odds ratios display a strong and monotonic temporal decay, from 16.6 for prior burglaries 0-2 days ago, to 2.0 for burglaries 6-24 months ago. To further scrutinize these differences, Wald test were used to assess the statistical significance between consecutive categories. As suggested by the patterns of overlap between the confidence intervals in Figure 1, two of the differences between odds ratios of consecutive categories are statistically significant (between 0-2 days and 3-6 days, and between 7-30 days and 1-6 months) but those between the two others are not (between 3-6 days and 7-30 days, and between 1-6 months and 7-24 months). However, the monotonically decreasing pattern in odds ratios over six consecutive categories (including the reference category) clearly supports the hypothesis.

Not only temporal but also spatial proximity appears to be relevant, as the proposed existence of spatial spillover effects is confirmed. An LSOA is not only more likely to be targeted if the burglar has targeted it before, but also if the burglar has targeted not this but another LSOA situated in its proximity. Being located in the proximity of an LSOA was operationalized as being 
located elsewhere in the same MSOA. The estimates of the MSOA variables clearly support this spillover hypothesis. All five temporally differentiated effects are positive and statistically significant. For example, the odds of an offender targeting an LSOA increase by a factor 3.6 if in the past two days the offender has committed a burglary elsewhere in the same MSOA that the LSOA is located in. If the prior burglary in the same MSOA was 3-6 days ago, the odds increase by a factor of 2.3. Thus, in line with the spillover hypothesis, burglars are not only likely to target areas previously targeted, but also those nearby.

The estimated effects of prior burglaries in the same MSOA also display a pattern of temporal decay, from an odds ratio of 3.6 for burglaries 0-2 days ago down to an odds ratio of 1.4 for burglaries 6-24 months ago. Despite the fact that the differences between consecutive odds ratios are not statistically significant, this monotonic decrease strongly suggests that the effect of recency also apply to the effects of burglaries committed nearby the focal LSOA.

For each category (e.g., ' $0-2$ days' or ' $3-6$ days') in Table 1, the LSOA estimate is larger than the MSOA estimate, suggesting that having committed a prior burglary in the same LSOA makes a burglar more likely to target the LSOA than just having committed a prior burglary in the same MSOA. In other words, the local effect is stronger than the spillover effect. This is to be expected, because the primary effect of previous burglaries is presumably that the burglar becomes aware of the direct environment of the targeted property (the LSOA). The awareness of the wider environment (the MSOA) is probably more diffuse and more likely to be a secondary effect. Wald tests of the differences between these estimates confirmed that in all five time categories the LSOA estimate is statistically significantly larger than the MSOA estimate.

As has been demonstrated in all prior discrete spatial choice studies, the distance to the burglar's own residence represents a friction to mobility and has therefore a negative effect: each kilometer a target area is farther away from the burglar's own home decreases the odds of being selected by a factor .58 , or by 42 percent.

Most but not all of the generic LSOA attributes (i.e. those that are measured without reference to the home location or the prior burglary locations of individual burglars) have statistically significant effects. Exceptions are the numbers of bus stations and the numbers of single-family residences. LSOAs with train stations are more likely to be targeted by burglars, presumably because these LSOA are visited by burglars during routine activities involving travel (e.g., work or school commutes), and are thus part of their awareness space.

The distance to the city center has a positive effect on the odds of the LSOA to be selected for burglary. The odds ratio of 1.10 indicates that the odds increase by 10 percent every kilometer an LSOA is farther away from the city center. In line with the expectations and results from other studies, the total number of households, the average house price, the ethnic diversity and the population turnover all increase the odds of an LSOA being chosen as a target area for burglary. 


\section{DISCUSSION}

This paper addressed the question of whether having burgled in a particular area, a burglar is more likely to target the same area again, and if so, whether this effect depends on the recency of the prior burglaries and whether it spills over to nearby areas.

Inspired by crime pattern theory it was hypothesized that burglars are more likely to target an area if (1) they have burgled in the area before, (2) the prior burglary was more recently committed, and (3) the area is in the proximity of an area recently targeted for a burglary. A discrete spatial choice model was used to analyze a set of police-recorded detected burglaries from the West Midlands (UK). The findings strongly support all three conjectures.

Our findings thus present good news for crime pattern theory. The theory itself, in particular the awareness space concept and its implications, builds on theoretical and empirical work in behavioral geography (Golledge \& Stimson, 1997). Our findings suggest that the way burglars go about choosing targets may not be all that different from the way ordinary people go about choosing places to perform legal activities. Their homes are important anchor points, they stick to choices made in the past, in particular the recent past, and when they change destinations, the new ones tend to be near previous ones.

This summary, however, describes blind habit formation without any reflection or learning. If a person makes the same choice over and over again even if it proves to be a mistake, no learning takes places. Rational choice theory, the perspective encapsulated by crime pattern theory, suggests that people make choices that are purposeful and based on expected costs and benefits. According to this theory, offender behavior would be incentive-driven and thus respond to gains and losses.

One point of possible critique on our design is that it assumes that burglaries are profitable and therefore provide incentives for returning to the previous target area. However, the data analyzed here contain detected burglaries only and these can of course be thought of as unsuccessful because they have resulted in arrest. Thus, one may ask why a burglar would choose to perpetrate another burglary in an area of a previous burglary that he has been arrested for. The answer could lie in the detection rate of burglary. On average no more than 10 percent of all residential burglaries are detected (Bernasco, 2014). Fear of detection might therefore not be a very decisive factor when burglars decide on where to commit offenses. Arrests after prior burglaries are possibly viewed as misfortunes rather than as mistakes, and may for that reason not affect subsequent target choices. Moreover, detected burglaries were not all solved immediately. If a considerable amount of time elapses between the offender committing the crime - or a series of crimes- and the offense(s) being detected, there is little reason to expect that police investigative effort would have affected offender decision-making. The distinction between completed and attempted burglaries might also be important, because the latter can also be considered unsuccessful burglaries. In such cases, offenders often fail to gain entry to a property 
or do not succeed to steal anything even if they entered the property. Learning burglars should be expected to return to locations of successfully completed burglaries and not to those where they failed.

The distinction between successful and unsuccessful burglaries is important and future research should therefore assess the extent to which the return of burglars to prior target areas is conditional on the success of the previous burglaries. Empirical research might start by adapting the (near) repeat research paradigms distinguishing between the likelihood of observing two types of burglary pairs close in time and space: pairs where the initial burglary was successful and pairs where it was not. If burglars learn from failure, the risk increase at short spatial and temporal distances should be significantly larger after successful burglaries than after unsuccessful ones. Burglary failure might be measured by detection (whether the burglar was arrested and charged), by the value of items stolen, or by successful entry (whether or not the burglar achieved entry into the property, i.e. whether it was an attempted or a completed burglary). Eventually, offender-based research might be required to reliably measure same offender involvement in successful, unsuccessful, detected and undetected burglaries.

Another unresolved issue is the potential confounding by patterns of co-offending. A substantial percentage of burglaries are committed by groups of burglars (percentages are based on police data and therefore probably underestimated). By analyzing burglaries as individual decisions only individual characteristics of the involved offender are used (his residential location and his prior burglaries), but the role of other offenders (their residential locations and their prior burglaries) in the burglary location choice is ignored. Clearly, more research is needed that analyzes crime location choices of co-offending groups (Bernasco, 2006).

As any study that explores the probability of an event as a function of similar prior events, our study suffers from the possibility that unobserved heterogeneity is attributed to state dependent variables. To explain, assume that some variable strongly affects burglary location choices. Further assume that this goes unobserved. If it affects location choice, it might influence all sequential choices made by an offender. Consequently, the effects of such an influential unobserved variable could be mistaken for the effect of prior choices. One potential bias is our inability to measure prior home locations of the burglars. Because offenders have a tendency to commit crimes not only near their current homes but also near former homes (Bernasco, 2010b), the finding that offenders commit crimes near locations of former crimes might in part be due to the fact that offenders commit crimes near their former homes, or other activity nodes that change over time. The effects observed here are however most dramatic for the most recently committed offenses, which seems inconsistent with this hypothesis, but ruling out such potential confounding effects will require more data on offender activity spaces, perhaps through ethnographic methods.

Finally, returning to the observation that human behavior in space is remarkably regular and predictable, we believe to have tentatively demonstrated that this consistency also applies to 
burglars and the locations they commit burglaries. Future research will hopefully teach us under which conditions this consistency is violated, and why.

\section{ACKNOWLEDGEMENTS}

This research was supported under Australian Research Council's Discovery Projects funding scheme (project number DP110100100, Understanding How Criminals Decide Where and When to Offend) and under the Netherlands Organization for Scientific Research's Innovational Research Incentives Scheme Vidi (project number 452-12-004). The authors would like to thank West Midlands police, and in particular Chief Superintendent Alex Murray, for providing the data analyzed in this paper, and the Editor and three anonymous reviewers for helpful comments. 


\section{REFERENCES}

Baudains, P., Braithwaite, A., \& Johnson, S. D. (2013). Target Choice During Extreme Events: A Discrete Spatial Choice Model of the 2011 London Riots. Criminology, 51(2), 251-285. doi: 10.1111/1745-9125.12004

Ben-Akiva, M. E., \& Lerman, S. R. (1985). Discrete Choice Analysis: Theory and Application to Travel Demand. Cambridge, MA: MIT Press.

Bennell, C., Mugford, R., Ellingwood, H., \& Woodhams, J. (2014). Linking Crimes Using Behavioural Clues: Current Levels of Linking Accuracy and Strategies for Moving Forward. Journal of Investigative Psychology and Offender Profiling, 11(1), 29-56. doi: 10.1002/jip.1395

Bernasco, W. (2006). Co-Offending and the Choice of Target Areas in Burglary. Journal of Investigative Psychology and Offender Profiling, 3, 139-155.

Bernasco, W. (2008). Them Again? Same Offender Involvement in Repeat and Near Repeat Burglaries. European Journal of Criminology, 5(4), 411-431.

Bernasco, W. (2010a). Modeling Micro-Level Crime Location Choice: Application of the Discrete Choice Framework to Crime at Places. Journal of Quantitative Criminology, 26(1), 113-138.

Bernasco, W. (2010b). A Sentimental Journey to Crime: Effects of Residential History on Crime Location Choice. Criminology, 48, 389-416.

Bernasco, W. (2014). Residential Burglary. In G. Bruinsma \& D. Weisburd (Eds.), Encyclopedia of Criminology and Criminal Justice (pp. 4381-4391): Springer New York.

Bernasco, W., \& Block, R. (2009). Where Offenders Choose to Attack: A Discrete Choice Model of Robberies in Chicago. Criminology, 47(1), 93-130.

Bernasco, W., Block, R., \& Ruiter, S. (2013). Go Where the Money is: Modeling Street Robbers' Location Choices. Journal of Economic Geography, 13(1), 119-143. doi: 10.1093/jeg/lbs005

Bernasco, W., \& Elffers, H. (2010). Statistical Analysis of Spatial Crime Data Handbook of quantitative criminology (pp. 699-724).

Bernasco, W., \& Kooistra, T. (2010). Effects of Residential History on Commercial Robbers' Crime Location Choices. European Journal of Criminology, 7(4), 251-265.

Bernasco, W., \& Nieuwbeerta, P. (2005). How Do Residential Burglars Select Target Areas? A New Approach to the Analysis of Criminal Location Choice. British Journal of Criminology, 45, 296-315.

Bernasco, W., \& Ruiter, S. (2014). Crime Location Choice. In G. J. N. Bruinsma \& D. Weisburd (Eds.), Encyclopedia of Criminology and Criminal Justice (pp. 691-699). New York, NY: Springer.

Bouhana, N., Johnson, S. D., \& Porter, M. (2014). Consistency and specificity in burglars who commit prolific residential burglary: Testing the core assumptions underpinning behavioural crime linkage. Legal and Criminological Psychology, n/a-n/a. doi: 10.1111/lcrp. 12050

Bowers, K. J., \& Johnson, S. D. (2004). Who Commits Near Repeats? A Test of the Boost Explanation. Western Criminology Review, 5(3), 12-24.

Bowers, K. J., \& Johnson, S. D. (2005). Domestic Burglary Repeats and Space-Time Clusters: The Dimensions of Risk. European Journal of Criminology, 2, 67-92. 
Bowers, K. J., Johnson, S. D., \& Pease, K. (2004). Prospective Hot-Spotting: The Future of Crime Mapping? Br J Criminol, 44, 641-658.

Brantingham, P. J., \& Brantingham, P. L. (2008). Crime Pattern Theory. In R. Wortley, L. Mazerolle, \& S. Rombouts (Eds.), Environmental Criminology and Crime Analysis (pp. 78-93). Cullompton, Devon, UK: Willan.

Breetzke, G. D. (2012). The effect of altitude and slope on the spatial patterning of burglary. Applied Geography, 34(0), 66-75. doi: 10.1016/j.apgeog.2011.10.017

Clare, J., Fernandez, J., \& Morgan, F. (2009). Formal Evaluation of the Impact of Barriers and Connectors on Residential Burglars' Macro-Level Offending Location Choices. Australian and New Zealand Journal of Criminology, 42, 139-158.

Clarke, R. V., Perkins, E., \& Smith Jr., D. J. (2001). Explaining Repeat Residential Burglaries: An Analysis of Property Stolen. In G. Farrell \& K. Pease (Eds.), Repeat Victimization. Crime Prevention Studies, Vol. 12. Monsey, New York: (pp. 119-132). Monsey, NY: Criminal Justice Press.

Cornish, D. B., \& Clarke, R. V. (Eds.). (1986). The Reasoning Criminal: Rational Choice Perspectives on Offending. New York: Springer.

Davies, T., \& Johnson, S. D. (2014). Examining the Relationship Between Road Structure and Burglary Risk Via Quantitative Network Analysis. Journal of Quantitative Criminology, 1-27. doi: 10.1007/s10940-014-9235-4

Dennett, A., \& Stillwell, J. (2008). Population turnover and churn: Enhancing understanding of internal migration in Britain through measures of stability. Population Trends, 134, 24-41.

Everson, S., \& Pease, K. (2001). Crime against the same person and place: Detection opportunity and offender targeting. In G. Farrell \& K. Pease (Eds.), Repeat victimization (pp. 199220). Monsey: Criminal Justice Press.

Farrell, G., \& Pease, K. (Eds.). (2001). Repeat Victimization (Vol. 12). Monsey: Criminal Justice Press.

Farrell, G., Phillips, C., \& Pease, K. (1995). Like Taking Candy. Why Does Repeat Victimization Occur? British Journal of Criminology, 35, 384-399.

Garcia-Retamero, R., \& Dhami, M. K. (2009). Take-the-best in expert-novice decision strategies for residential burglary. Psychonomic Bulletin \& Review, 16(1), 163-169.

Golledge, R. G., \& Stimson, R. J. (1997). Spatial Behavior: A Geographic Perspective. New York: The Guilford Press.

Grubesic, T., \& Mack, E. (2008). Spatio-Temporal Interaction of Urban Crime. Journal of Quantitative Criminology, 24(3), 285-306.

Haining, R. (2012). Ecological Analysis of Urban Offence and Offender Data. In V. Ceccato (Ed.), The Urban Fabric of Crime and Fear (pp. 141-163): Springer Netherlands.

Johnson, D. (2013). The space/time behaviour of dwelling burglars: Finding near repeat patterns in serial offender data. Applied Geography, 41, 139-146. doi:

10.1016/j.apgeog.2013.04.001

Johnson, S. D. (2008). Repeat burglary victimisation: a tale of two theories. Journal of Experimental Criminology, 4(3), 215-240.

Johnson, S. D., Bernasco, W., Bowers, K., Elffers, H., Ratcliffe, J. H., Rengert, G. F., \& Townsley, M. T. (2007). Space-Time Patterns of Risk: A Cross National Assessment of Residential Burglary Victimization. Journal of Quantitative Criminology, 23, 201-219.

Johnson, S. D., \& Bowers, K. J. (2004a). The Burglary as Clue to the Future: The Beginnings of Prospective Hot-Spotting. European Journal of Criminology, 1, 237-255. 
Johnson, S. D., \& Bowers, K. J. (2004b). The Stability of Space-Time Clusters of Burglary. British Journal of Criminology, 44, 55-65.

Johnson, S. D., \& Bowers, K. J. (2010). Permeability and Burglary Risk: Are Cul-de-Sacs Safer? Journal of Quantitative Criminology, 26(1), 89-111. doi: 10.1007/s10940-009-9084-8

Johnson, S. D., Bowers, K. J., \& Hirschfield, A. (1997). New Insights Into the Spatial and Temporal Distribution of Repeat Victimization. British Journal of Criminology, 37, 224241.

Johnson, S. D., \& Summers, L. (2014). Testing Ecological Theories of Offender Spatial Decision Making Using a Discrete Choice Model. Crime \& Delinquency. doi: 10.1177/0011128714540276

Johnson, S. D., Summers, L., \& Pease, K. (2009). Offender as Forager? A Direct Test of the Boost Account of Victimization. Journal of Quantitative Criminology, 25(2), 181-200.

Lammers, M., Menting, B., Ruiter, S., \& Bernasco, W. (2015). Biting Once, Twice: The Influence of Prior on Current Crime Location Choice. Criminology, 52.

Markson, L., Woodhams, J., \& Bond, J. W. (2010). Linking serial residential burglary: comparing the utility of modus operandi behaviours, geographical proximity, and temporal proximity. Journal of Investigative Psychology and Offender Profiling, 7(2), 91107. doi: 10.1002/jip.120

McFadden, D. (1978). Quantitative methods for analyzing travel behaviour of individuals: Some recent developments. In D. A. Hensher \& P. R. Stopher (Eds.), Behavioural Travel Modeling (pp. 279-318). London, UK: Croom Helm London.

McFadden, D. (2001). Disaggregate Behavioral Travel Demand's RUM Side: A 30-Year Retrospective. In D. A. Henscher (Ed.), Travel Behavior Research; The Leading Edge (pp. 17-63). Oxford: Pergamon.

Mohler, G. O., Short, M. B., Brantingham, P. J., Schoenberg, F. P., \& Tita, G. E. (2011). SelfExciting Point Process Modeling of Crime. Journal of the American Statistical Association, 106(493), 100-108. doi: 10.1198/jasa.2011.ap09546

Nee, C., \& Meenaghan, A. (2006). Expert Decision Making in Burglars. British Journal of Criminology, 46, 935-949.

Pease, K. (1998). Repeat victimisation: Taking stock. London: Police Research Group, Home Office.

Pitcher, A. B., \& Johnson, S. D. (2011). Exploring Theories of Victimization Using a Mathematical Model of Burglary. Journal of Research in Crime and Delinquency, 48(1), 83-109. doi: 10.1177/0022427810384139

Polvi, N., Looman, T., Humphries, C., \& Pease, K. (1991). The Time-Course of Repeat Burglary Victimisation. British Journal of Criminology, 31, 411-414.

Ratcliffe, J. H., \& McCullagh, M. J. (1998). Identifying Repeat Victimization with GIS. British Journal of Criminology, 38, 651-662.

Rengert, G. F., \& Wasilchick, J. (2000). Suburban Burglary: A Tale of Two Suburbs. Springfield, IL: Charles C. Thomas.

Song, C., Qu, Z., Blumm, N., \& Barabasi, A.-L. (2010). Limits of Predictability in Human Mobility. Science, 327(5968), 1018-1021. doi: 10.1126/science.1177170

Sturgis, P., Brunton-Smith, I., Kuha, J., \& Jackson, J. (2013). Ethnic diversity, segregation and the social cohesion of neighbourhoods in London. Ethnic and Racial Studies, 37(8), 12861309. doi: 10.1080/01419870.2013.831932 
Summers, L., Johnson, S. D., \& Rengert, G. F. (2010). The Use of Maps in Offender Interviewing. In W. Bernasco (Ed.), Offenders on offending: Learning about crime from criminals. Cullompton, UK: Willan.

Tonkin, M., Santtila, P., \& Bull, R. (2012). The linking of burglary crimes using offender behaviour: Testing research cross-nationally and exploring methodology. Legal and Criminological Psychology, 17(2), 276-293. doi: 10.1111/j.2044-8333.2010.02007.x

Tonkin, M., Woodhams, J., Bull, R., Bond, J. W., \& Palmer, E. J. (2011). Linking Different Types of Crime Using Geographical and Temporal Proximity. Criminal Justice and Behavior, 38(11), 1069-1088. doi: 10.1177/0093854811418599

Townsley, M., Birks, D., Bernasco, W., Ruiter, S., Johnson, S. D., Baum, S., \& White, G. (2013). Burglar target selection: A cross-national comparison.

Townsley, M. T., Homel, R., \& Chaseling, J. (2003). Infectious Burglaries: A Test of the Near Repeat Hypothesis. British Journal of Criminology, 43, 615-633.

Tseloni, A., \& Pease, K. (2003). Repeat Personal Victimization. 'Boosts' or 'Flags'? British Journal of Criminology, 43, 196-212.

Wilcox, A. R. (1973). Indices of Qualitative Variation and Political Measurement. The Western Political Quarterly, 26(2), 325-343. doi: 10.2307/446831

Woodhams, J., Hollin, C. R., \& Bull, R. (2007). The psychology of linking crimes: A review of the evidence. Legal and Criminological Psychology, 12(2), 233-249. doi: $10.1348 / 135532506 \times 118631$

Wright, R. T., Brookman, F., \& Bennett, T. (2006). The Foreground Dynamics of Street Robbery in Britain. British Journal of Criminology, 46, 1-15.

Wright, R. T., \& Decker, S. H. (1994). Burglars on the Job: Streetlife and Residential Break-Ins. Boston: Northeastern University Press.

Wu, L., Liu, X., Ye, X., Leipnik, M., Lee, J., \& Zhu, X. Permeability, space syntax, and the patterning of residential burglaries in urban China. Applied Geography(0). doi: 10.1016/j.apgeog.2014.12.001

Ye, X., Xu, X., Lee, J., Zhu, X., \& Wu, L. Space-time interaction of residential burglaries in Wuhan, China. Applied Geography(0). doi: 10.1016/j.apgeog.2014.11.022 


\section{Appendix}

Table A1: Conditional Logit Model Estimates (Odds Ratios and 95\% Confidence Intervals) of Burglars' Choice of Target LSOA. Model Applies to 3,337 Burglaries Committed by 2,143 Offenders. Number of LSOAs $=1,687$. McFadden's Pseudo $\mathrm{R}^{2}=.31$

\begin{tabular}{|c|c|c|c|}
\hline & \multirow[t]{2}{*}{ Odds Ratio } & \multicolumn{2}{|c|}{$95 \%$ Confidence Interval } \\
\hline & & Lower boundary & Upper boundary \\
\hline \multicolumn{4}{|l|}{ Prior Burglary Same LSOA: } \\
\hline $0-2$ days & $16.59 * * *$ & 13.13 & 21.97 \\
\hline $3-7$ days & $5.83^{* * *}$ & 4.09 & 8.31 \\
\hline 8-30 days & $4.33 * * *$ & 3.38 & 5.55 \\
\hline $1-6$ months & $2.23 * * *$ & 1.79 & 2.76 \\
\hline 7-24 months & $2.02 * * *$ & 1.53 & 2.66 \\
\hline None $<24$ months (ref.) & 1 & 1 & 1 \\
\hline \multicolumn{4}{|l|}{ Prior Burglary Same MSOA: } \\
\hline $0-2$ days & $3.59 * * *$ & 2.37 & 5.45 \\
\hline $3-7$ days & $2.31 * * *$ & 1.59 & 3.32 \\
\hline $8-30$ days & $1.99 * * *$ & 1.65 & 2.41 \\
\hline $1-6$ months & $1.64 * * *$ & 1.31 & 2.06 \\
\hline $7-24$ months & $1.43 * * *$ & 1.19 & 1.71 \\
\hline None $<24$ months (ref.) & 1 & 1 & 1 \\
\hline Distance $(\mathrm{km})$ & $0.58 * * *$ & 0.56 & 0.61 \\
\hline Bus Station & 0.74 & 0.52 & 1.05 \\
\hline Train Station & $1.24 *$ & 1.03 & 1.49 \\
\hline Distance city center $(\mathrm{km})$ & $1.10^{*}$ & 1.07 & 1.13 \\
\hline Households $(1,000 \#)$ & $2.91 * * *$ & 1.82 & 4.63 \\
\hline Single Family Residences (10\%) & 0.96 & 0.89 & 1.02 \\
\hline Mean house price $(1,000 £))$ & $1.01 * * *$ & 1.01 & 1.01 \\
\hline Ethnic Diversity (10\%) & $1.05 * * *$ & 1.01 & 1.09 \\
\hline Population Turnover (10\%) & $1.06 * * *$ & 1.01 & 1.12 \\
\hline
\end{tabular}

